\title{
BMJ Open Cohort profile: the AUstralian Twin BACK pain and physical activity study (AUTBACK study)
}

\author{
Ana Paula Carvalho-e-Silva (D , , ${ }^{1}$ Marina B Pinheiro, ${ }^{1,2,3}$ Manuela L Ferreira, ${ }^{4}$ \\ Markus Hübscher, ${ }^{5}$ Lucas Calais-Ferreira, ${ }^{6}$ Paulo H Ferreira ${ }^{1,7}$
}

To cite: Carvalho-e-Silva AP, Pinheiro MB, Ferreira ML, et al. Cohort profile: the AUstralian Twin BACK pain and physical activity study (AUTBACK study). BMJ Open 2020;10:e036301. doi:10.1136/ bmjopen-2019-036301

- Prepublication history for this paper is available online. To view these files, please visit the journal online (http://dx.doi. org/10.1136/bmjopen-2019036301).

Received 11 December 2019 Revised 17 April 2020 Accepted 28 May 2020

Check for updates

(c) Author(s) (or their employer(s)) 2020. Re-use permitted under CC BY-NC. No commercial re-use. See rights and permissions. Published by BMJ.

For numbered affiliations see end of article.

Correspondence to

Dr Ana Paula Carvalho-e-Silva; amou6759@uni.sydney.edu.au

\section{ABSTRACT}

Purpose Despite the growing evidence that physical activity and familial factors play a role in low back pain (LBP), there is a lack of robust longitudinal studies that (1) investigate the types and dosages of physical activity that are protective or harmful for LBP, (2) employ objective measures of physical activity and (3) conduct appropriate adjustment for confounders. The AUstralian Twin BACK (AUTBACK) study was established to elucidate the longitudinal LBP-physical activity relationship with the benefits of controlling for familial (both genetic/nongenetic) factors that may influence physical activity engagement and LBP.

Participants Participants are twins registered at Twins Research Australia (TRA), older than 18 years, with access to internet. We collected data on LBP status (weekly) and physical activity levels (monthly) for 12 months as well as a wide range of health, lifestyle and physical activity (objective, self-reported, including different types and dosages) data.

Findings to date We included 401 twins, 157 being complete twin pairs $(n=314)$. Lifetime prevalence of LBP was $85 \%$. Participants spent $61 \%$ of their week in sedentary time and only $4 \%$ in moderate/vigorous intensity physical activity (accelerometer). So far, 168 participants ( $40 \%$ of the sample) have completed the 12-month follow-up. A total of 7150 weekly (LBP status) and 1763 monthly questionnaires (physical activity status) have been answered (92\% response rate).

Future plans The 12-month follow-up will be completed by June 2020 . This cohort represents a novel and comprehensive resource for researchers in the field, and includes high-quality, and frequent data on LBP and physical activity. It allows the investigation of genetic and shared environmental factors on the LBP-physical activity relationship. The AUTBACK group has planned a number of projects, with the main one being the investigation of the influence of physical activity on recurrence of LBP. Data linkage opportunities are available, including with other studies conducted by TRA.

\section{INTRODUCTION}

It is estimated that $83 \%$ of the world population will report at least one episode of low back pain (LBP) during their lifetime, ${ }^{1}$ with 3.7 million people reporting LBP in Australia in 2014-2015..$^{2}$ Although it is well known that

\section{Strengths and limitations of this study}

The AUstralian Twin BACK (AUTBACK) is collecting high-quality repeated measures of low back pain and physical activity with weekly pain and monthly physical activity measures.

- The sample of AUTBACK includes twins from all states in Australia. The inclusion of twins as participants allow for innovative familial and genetic analyses.

- Although objective assessment of physical activity was not available from all participants, it is still available from $92 \%$ of the sample.

LBP significantly impacts people's quality of life, its specific causes are unclear. ${ }^{34}$ Risk factors for LBP are poorly understood, with the most consistently reported risk factor for a new episode of LBP being a previous episode. ${ }^{5}$ For chronic LBP, some modifiable, but weak, risk factors have been previously identified, including smoking, psychological distress and physical inactivity. ${ }^{6}$

Among the modifiable risk factors for LBP, physical activity is particularly promising. ${ }^{78}$ The health benefits associated with regular leisure physical activity are well established. $^{79-11}$ People who engage in moderate or vigorous activity at least three times per week have on average $39 \%$ less risk of cardiovascular mortality, ${ }^{9} 10$ and four additional years in life expectancy compared with those who do not engage in physical activity. ${ }^{11}$ Although clinical guidelines recommend engagement in leisure physical activity as a strategy to manage and reduce the risk of $\mathrm{LBP}^{12}$ it is still unclear what types and doses of physical activity are harmful or protective for LBP. People with chronic or persistent LBP who are physically active (ie, engage in at least 3 hours of moderate activities per week) have a better 1-year prognosis in terms of disability and pain intensity when compared with those who are inactive during leisure 


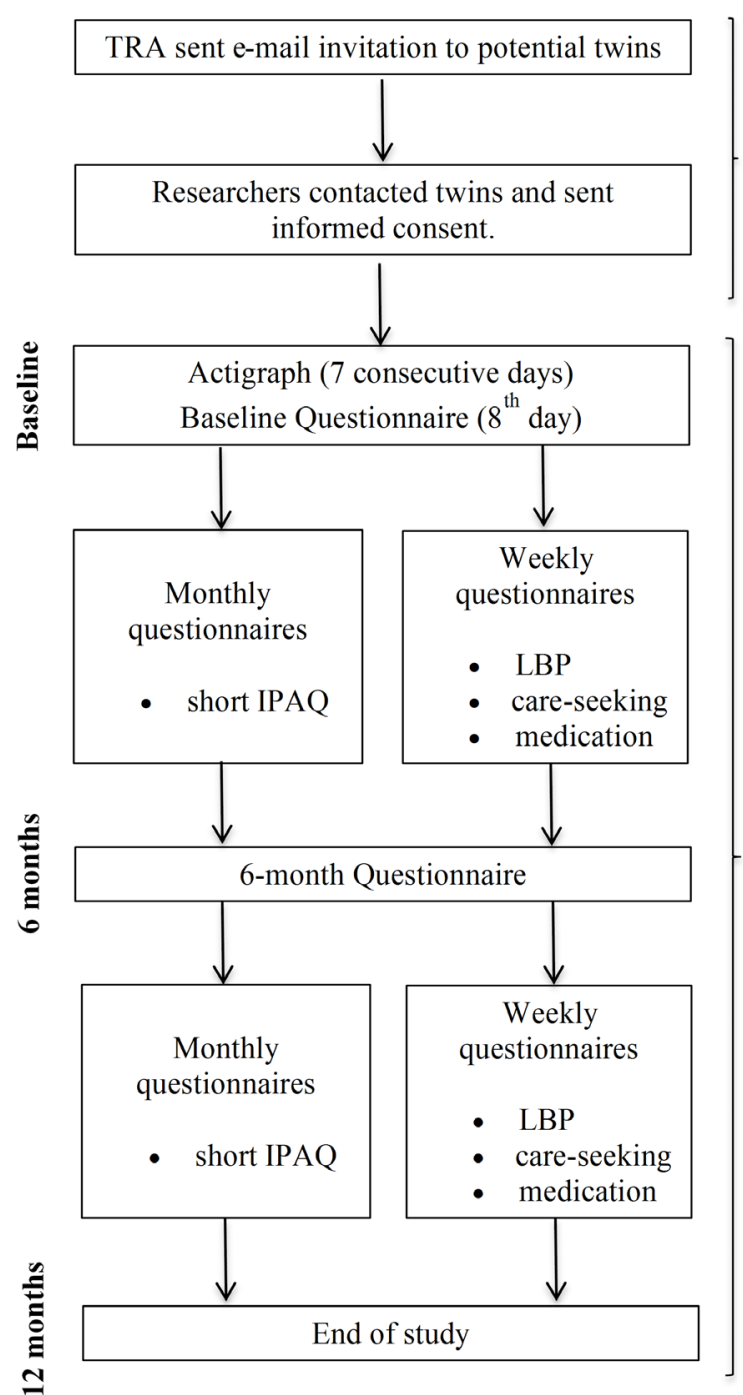

Figure 1 AUTBACK study flow chart. AUTBACK, AUstralian Twin BACK; IPAQ, International Physical Activity Questionnaire; LBP, low back pain; TRA, Twins Research Australia.

time (ie, report spending most of their leisure time sitting, and watching television). ${ }^{13}$ Moreover, a recent systematic review, including people free of chronic-LBP at study inception, indicated that engagement in moderate (1-3 times per week), or vigorous/high ( $\geq 3-4$ times per week) physical activity during leisure time is associated with a $11 \%-16 \%$ decreased risk of developing chronic LBP. ${ }^{14}$ However, the impact of the interaction between different types of physical activities on LBP is intriguing. For example, people who engage in heavy domestic and recreational physical activity report a higher prevalence of LBP when compared with those who engage in heavy domestic physical activity only. ${ }^{15}$ Given that these interactions are complex and not well understood, it is difficult for clinicians to advise patients on the role of physical activity for LBP.

One potential explanation for the lack of clarity on the relationship between $\mathrm{LBP}$ and physical activity is the presence of methodological differences between previous studies. First, to date, most studies have focused on the effect of a single type of physical activity (eg, leisure time or work related) on LBP. ${ }^{1416}$ However, physical activity is a complex behaviour often characterised by a combination of different dimensions (type, frequency, duration and intensity), and domains (leisure time, household, transportation and work related). Second, most of the previous studies in this field have used self-reported questionnaires to assess physical activity. ${ }^{18}$ Although questionnaires are useful instruments to quantify physical activity repeatedly over time, non-objective measurements often overestimate people's engagement in leisure physical activity and underestimate engagement in sedentary time. ${ }^{19}$ Therefore, self-reported tools should be supplemented by objective measures so that physical activity is validly assessed. ${ }^{2021}$ Third, there is a lack of robust longitudinal studies with multiple data points assessing the relationship between physical activity and LBP outcomes. ${ }^{18} \mathrm{~A}$ person's LBP status and physical activity engagement may vary over time, ${ }^{22}$ and therefore, the collection of data at frequent and multiple time points is critical to capture individual changes. Finally, it is known that genetics can explain up to $67 \%$ of population variance in LBP. ${ }^{2324}$ Twin studies offer a great opportunity to account for the influences of genetic and early shared environmental factors on the risk of developing a condition, ${ }^{25}$ and therefore, may allow a more precise estimation of the relationship between physical activity and LBP than non-twin studies.

In light of the current gaps in the literature on the relationship between physical activity and LBP, we have designed and established the AUstralian Twin BACK (AUTBACK) study. This study was set up to expand the pilot case-control AUTBACK study conducted in $2014,{ }^{26}$ and therefore, allowing to answer other questions regarding the relationship between physical activity (including objectively measured physical activity) and LBP. This is the first cohort study to collect high quality, comprehensive and frequent data on LBP and physical activity in twins. The data collected can help to answer some of the questions related to the role of physical activity in LBP (eg, recurrence or incidence of LBP), and consequently produce insights on a potential target for the prevention and management of LBP. In this manuscript, we describe the study design, data collection procedures, participants' characteristics, baseline and follow-up data collected so far.

\section{COHORT DESCRIPTION \\ Study design}

AUTBACK is an ongoing study with a sample of twins living in Australia who are registered at Twins Research Australia (TRA), formerly known as the Australian Twin Registry-an Australian national twin registry of more than 80000 twins who have volunteered to participate in research studies. The study was established to collect frequent and comprehensive measures of LBP (eg, pain levels, care-seeking behaviour) on a weekly basis, and 
Table 1 Description of data collected

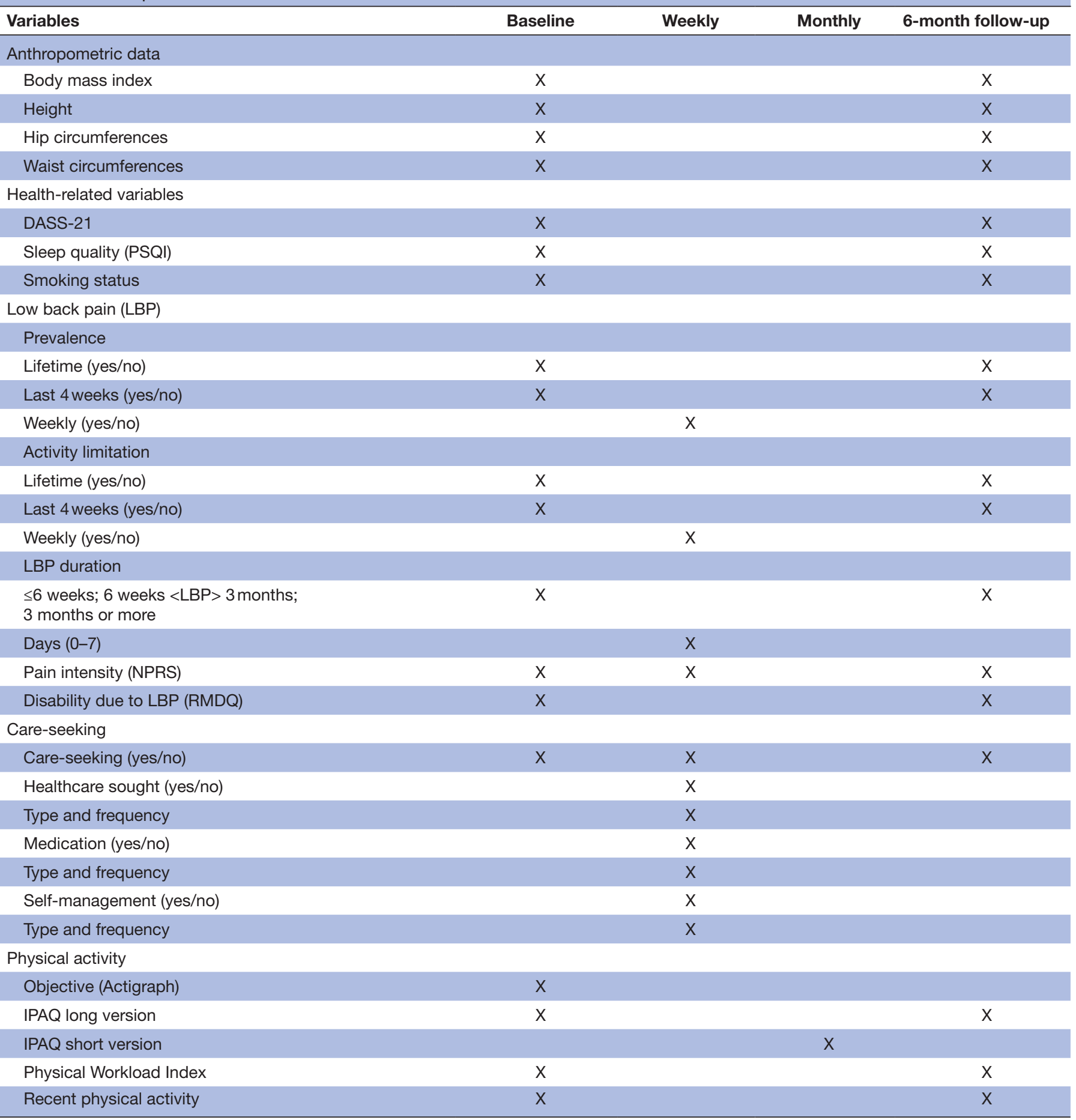

DASS-21, Depression Anxiety Stress Scale; IPAQ, International Physical Activity Questionnaire; NPRS, Numerical Pain Rating Scale; PSQI, Pittsburgh Sleep Quality Index; RMDQ, Roland Morris Disability Questionnaire.

physical activity (objectively assessed at baseline, and self-reported during monthly follow-ups) status during a 12-month period. ${ }^{26}$ We also assessed other health-related data (eg, smoking, mental health and sleep quality) at study inception. All surveys are collected electronically using a system built specifically for the purpose of this project.

\section{Participants' eligibility and recruitment}

Recruitment for the AUTBACK cohort occurred from October 2015 to June 2019. Initially, TRA invited a total of 3842 twins (1921 twin pairs) to participate in the study. From the total number of twins approached, $644(20 \%)$ individuals' expressed interest to participate in the study and were contacted by study staff. Eligible participants 
Table 2 Sample characteristics for the AUTBACK sample at baseline

\begin{tabular}{lll}
\hline Variables & N & $\begin{array}{l}\text { Mean } \pm \text { SD or } \\
\%\end{array}$ \\
\hline Total sample & \\
$\quad$ Age (years) & 401 & $53 \pm 13$ \\
\hline Body mass index & 397 & $25 \pm 4$ \\
$\quad$ Gender (female) & 294 & 73 \\
\hline Zygosity & \\
$\quad$ Monozygotic & 262 & 65 \\
\hline Dizygotic & 139 & 35 \\
\hline Depression (DASS-21 range 0-42) & 401 & \\
$\quad$ Depression (range 0-42) & 401 & $3.8 \pm 6.7$ \\
$\quad$ Anxiety (range 0-42) & 401 & $3.2 \pm 5.4$ \\
$\quad$ Stress (range 0-42) & 397 & $7.3 \pm 7.6$ \\
Sleep Quality Index (PSQI range & 220 & $6.4 \pm 3.1$ \\
0-21) & & \\
\hline
\end{tabular}

\begin{tabular}{lrr|} 
Smoking status & & \\
Non-smoker & 324 & 82 \\
Ex-smoker & 56 & 15 \\
\hline Occasional smoker & 6 & 1 \\
Current smoker & 10 & 2 \\
\hline States and Territories & & \\
Australian Capital Territory & 13 & 3 \\
\hline New South Wales & 95 & 24 \\
\hline Northern Territory & 7 & 2 \\
\hline Queensland & 80 & 20 \\
South Australia & 29 & 7 \\
\hline Tasmania & 9 & 2 \\
Victoria & 115 & 29 \\
Western Australia & 53 & 13 \\
Complete Pairs only & 314 & \\
\hline Z & &
\end{tabular}

Zygosity

\begin{tabular}{lrr} 
Monozygotic-female/female & 178 & 57 \\
Monozygotic-male/male & 42 & 13 \\
Dizygotic-female/female & 56 & 18 \\
Dizygotic-male/male & 18 & 5 \\
Dizygotic female/male & 20 & 6 \\
Individual twins only & 87 & \\
Gender (female) & 50 & 57 \\
Zygosity & & \\
Monozygotic & 41 & 47 \\
Dizygotic & 46 & 53 \\
\hline
\end{tabular}

Individuals twins only: incomplete pair.

AUTBACK, AUstralian Twin BACK; DASS-21, Depression Anxiety

Stress Scale; PSQI, Pittsburgh Sleep Quality Index.

had to be at least 18 years old with internet access via computer or smartphone and an active email account. Complete pairs (both twins in the pair), or incomplete pairs (only one twin in the pair) were eligible to participate in the study. Twins with any self-reported serious spinal pathology (eg, inflammatory, metastatic or infectious disease of the spine), pregnant women, and those who had undergone spinal surgery in the last 12 months were not eligible to take part in this study. Eligible participants received an email with a link to a website. On the study website, participants had access to the study information and an online consent form. All included participants consent to participate in the study and are being followed for 12 months. Data are collected at baseline, monthly (short International Physical Activity Questionnaire (IPAQ)), at 6 months (midterm) and weekly (LBP status) (figure 1) (table 1). All data are stored on the University of Sydney server and collected electronically through a specifically designed web-based tool.

\section{Patient involvement}

There was no patient or public involvement in this study.

\section{Procedures}

Once participants gave their consent and confirmed their availability, objective data on physical activity were collected using an accelerometer (Actigraph GT1M/ GT3X model), which is a device widely used in clinical research and has shown good reliability and validity to assess physical activity ${ }^{27}$. The ActiGraph device was sent via post to be worn for seven consecutive days. Participants were asked to wear the device on the right hip (with an elastic belt) during their waking hours ${ }^{27} 29$ and received an SMS reminder on the third and fifth day. They were instructed to remove the device during water activities and bathing and to fill in a diary reporting their daily activities. The ActiLife V.6.13.3 software was used for data processing and extraction. The accelerometer was set up on $30 \mathrm{~Hz}$ frequency, data were downloaded in $60 \mathrm{~s}$ epoch, and were considered valid if the participant had worn it for at least $600 \mathrm{~min}$ in a minimum of 4 days. ${ }^{29}{ }^{30}$ To classify non-wear time, Actigraph data were validated using the Troiano algorithm-a common automated algorithm using criteria proposed by Troiano. ${ }^{30}$ This algorithm defines the non-wear time when there is a minimum of 60 consecutive minutes of 0 activity counts, with allowance up 2 to minutes of counts between 0 and 100 . This algorithm has been used by several populationbased studies to detect and eliminate the non-wear time interval, in which no activity is performed. ${ }^{31}$ Participants wore the Actigraph before answering the baseline questionnaire, and on the eighth day postwearing the device they were emailed a link to respond to the electronic baseline questionnaire.

\section{Baseline questionnaire}

We collected data on LBP lifetime prevalence, LBP in the last 4 weeks, pain intensity, symptom duration, activity limitation, disability and care-seeking due to LBP. Only participants reporting a history of LBP (ie, lifetime prevalence) were asked to answer the question regarding the presence of pain in the last 4 weeks. Only those answering 


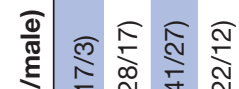

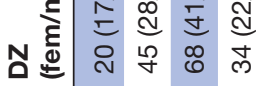

운

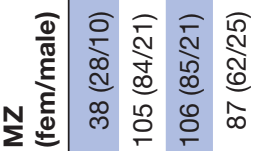

$\frac{\text { ก }}{\stackrel{2}{\infty}}$

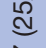

ले

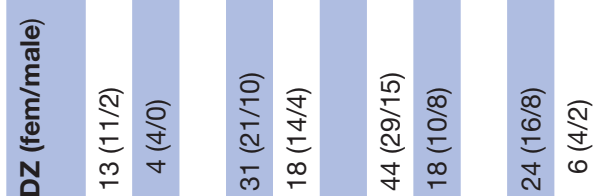

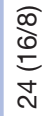

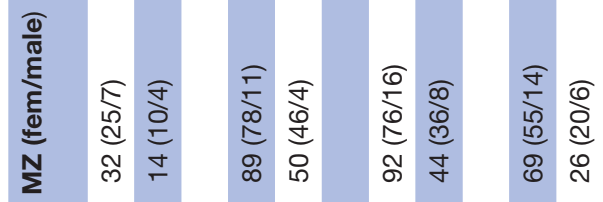

$\frac{\substack{\sigma \\ 0}}{8}$

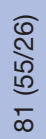

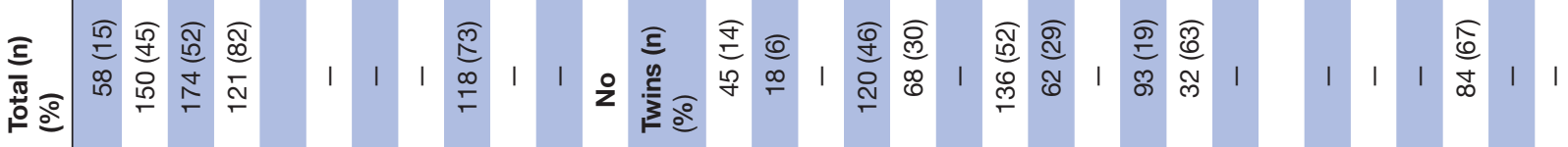

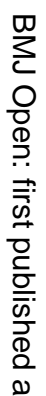

$\overrightarrow{0}$

$\vec{\omega}$

응.

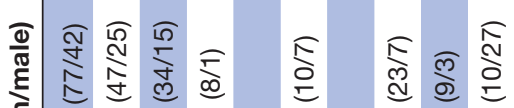
N.
할

है

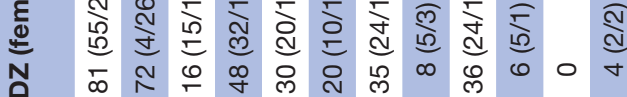

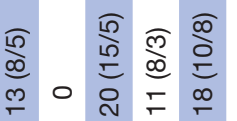

$\stackrel{\infty}{\nu}$ ब

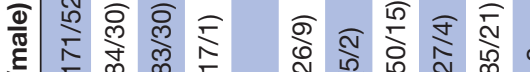

$\widehat{\bar{o}}$

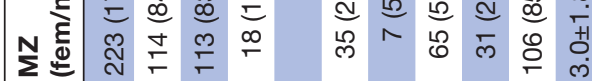

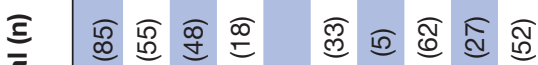
응

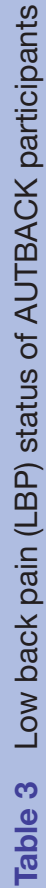

$\frac{\frac{0}{0}}{\frac{0}{\pi}}$

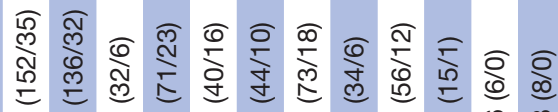

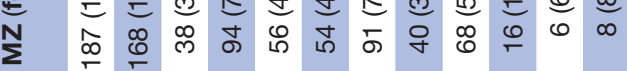

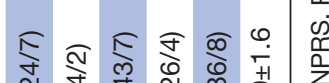

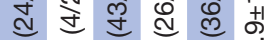
ले 0 मे वे च

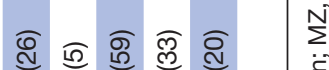

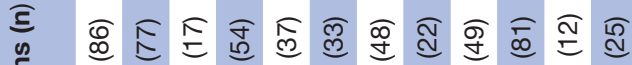

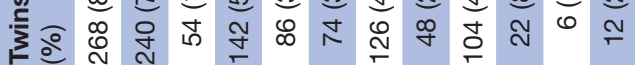


Table 4 Descriptive data on physical activity

\begin{tabular}{|c|c|c|c|c|}
\hline \multirow[b]{2}{*}{ Variables } & \multicolumn{2}{|c|}{ All participants } & \multicolumn{2}{|c|}{ Complete pairs } \\
\hline & $\mathbf{N}$ & Mean \pm SD & $\mathbf{N}$ & Mean \pm SD \\
\hline \multicolumn{5}{|l|}{ Actigraph } \\
\hline Light intensity (min/week) & 369 & $1894 \pm 565$ & 276 & $1893 \pm 567$ \\
\hline Moderate-to-vigorous intensity (min/week) & 369 & $210 \pm 150$ & 276 & $213 \pm 153$ \\
\hline \multicolumn{5}{|l|}{ IPAQ long-form } \\
\hline Sitting time (min/week) & 399 & $2516 \pm 1353$ & 312 & $2590 \pm 1364$ \\
\hline Walking time (min/week) & 397 & $525 \pm 683$ & 310 & $470 \pm 616$ \\
\hline Moderate-to-vigorous intensity (min/week) & 396 & $939 \pm 1049$ & 310 & $863 \pm 959$ \\
\hline Transportation (MET-min/week) & 397 & $698 \pm 1101$ & 310 & $602 \pm 957$ \\
\hline Domestic and Garden (MET-min/week) & 397 & $2006 \pm 2784$ & 310 & $1893 \pm 2642$ \\
\hline Leisure-time (MET-min/week) & 397 & $1421 \pm 2005$ & 310 & $1366 \pm 2024$ \\
\hline Physical Workload Index & 371 & $11.4 \pm 9.1$ & 292 & $11.2 \pm 9.1$ \\
\hline
\end{tabular}

IPAQ, International Physical Activity Questionnaire.

yes to the presence of pain in the past 4 weeks were asked about activity limitation, duration, intensity and whether they were receiving any treatment for LBP. Pain intensity was assessed using the 11-point Numerical Pain Rating Scale (NPRS) ${ }^{32}$ Activity limitation was assessed by the question 'Was this pain bad enough to limit your usual activities or change your daily routine for more than 1 day?', and LBP symptom duration by the question: 'for how long have you been experiencing LBP?' Participants' disability level was assessed by the Roland Morris Disability Questionnaire (RMDQ) ${ }^{33}$ The total RMDQ score was obtained by the sum of the items ticked, with higher scores representing higher disability levels. ${ }^{34}$ These outcomes and assessment methods are aligned with the best practice recommendations for conducting epidemiological studies on LBP. ${ }^{35}$

Data on self-reported physical activity at baseline were collected using different tools, including the IPAQ long version, ${ }^{19} 36$ the Physical Workload Index Questionnaire $^{37}$ and the Recent Physical Activity Questionnaire. ${ }^{38}$ These questionnaires provide data on different types of physical activity, for example, recreational, leisure, work related and dosage (duration, frequency and intensity) of physical activity. The IPAQ long form assesses time spent and the intensity of five domains of physical activities: work, transport related, household, leisure time and sitting time. ${ }^{36}$ Scores on IPAQ are reported as total time (min) and Metabolic Equivalents (MET) (min) spent in different activities and domains during a week, and were calculated according to the IPAQ protocol. ${ }^{39}$ The Physical Workload Index questionnaire was used to assess the workload forces on the lumbar spine while in different postures described in the questionnaire. ${ }^{37}$ The total workload force was calculated according to the questionnaire protocol formula. $^{37}$

We have also collected, at baseline, other variables known to have an impact on LBP and physical activity, including depression, sleep quality, smoking status, anthropometric and demographic data. The Depression Anxiety Stress Scale (DASS-21) ${ }^{40}$ was used to assess participants' levels of depression and anxiety. The cut-off points for each component were: depression $\leq 9$; anxiety $\leq 7$ and stress $\leq 14 .{ }^{40}$ Sleep quality was collected using the Pittsburgh Sleep Quality Index (PSQI) ${ }^{41}$ Scores for this questionnaire range from 0 to 21 points, with scores higher than 5 points regarded as poor sleep quality. ${ }^{41}$ Smoking status was collected using the question 'regarding your smoking habit, how would you classify yourself?': nonsmoker, ex-smoker, occasional or current smoker. Participants also provided their date of birth, weight, height and hip and waist circumferences. The weight and height measurements were used to calculate body mass index (BMI). Waist and hip circumferences, measured using a tape measure posted to participants together with detailed instructions in how to perform these measurements, and these information can be used to calculate waist-hip ratio in order to classify participants' central obesity. ${ }^{42}$

Follow-up questionnaires (weekly, monthly and midterm)

After the completion of the baseline questionnaire, participants received weekly SMS or email and monthly questionnaires for 12 months. In the weekly survey, 
Table 5 Weekly prevalence of LBP in participants with complete 12-month follow-up data

\begin{tabular}{|c|c|c|c|}
\hline Variables & $\begin{array}{l}\mathrm{N} \\
\text { (participants) }\end{array}$ & $\begin{array}{l}\mathrm{N} \\
\text { (12-month } \\
\text { episodes) }\end{array}$ & $\begin{array}{l}\text { Average } \\
\text { of days or } \\
\text { intensity } \\
(0-10)\end{array}$ \\
\hline Text message sent & 168 & 7150 & \\
\hline $\begin{array}{l}\text { Text message } \\
\text { completion }\end{array}$ & 168 & 6945 & \\
\hline $\begin{array}{l}\text { LBP last } 7 \text { days } \\
\text { (yes) }\end{array}$ & 131 & 1422 & \\
\hline LBP duration (days) & 131 & 1325 & $35.1 \pm 56.0$ \\
\hline $\begin{array}{l}\text { LBP intensity } \\
\text { (intensity) (0-10) }\end{array}$ & 130 & 1323 & $3.2 \pm 1.8^{*}$ \\
\hline $\begin{array}{l}\text { Activity limitation } \\
\text { (yes) }\end{array}$ & 70 & 277 & \\
\hline Work activities & 27 & 148 & $17.3 \pm 47.1$ \\
\hline Social activities & 21 & 62 & $7.4 \pm 12.6$ \\
\hline Sports & 38 & 73 & $4.1 \pm 5.6$ \\
\hline Hobbies & 18 & 54 & $6.0 \pm 8.2$ \\
\hline Intimacy & 23 & 73 & $12.5 \pm 27.1$ \\
\hline Chores & 38 & 179 & $14.8 \pm 39.8$ \\
\hline $\begin{array}{l}\text { Treatments sought } \\
\text { (yes) }\end{array}$ & 55 & 259 & \\
\hline $\begin{array}{l}\text { General } \\
\text { practitioner }\end{array}$ & 8 & 12 & $1.5 \pm 1.1$ \\
\hline Physiotherapist & 22 & 97 & $4.4 \pm 6.2$ \\
\hline Chiropractor & 10 & 40 & $4.0 \pm 2.7$ \\
\hline $\begin{array}{l}\text { Emergency } \\
\text { department }\end{array}$ & 2 & 3 & $1.5 \pm 0.7$ \\
\hline Surgery & 3 & 4 & $1.3 \pm 0.6$ \\
\hline Other & 16 & 67 & $2.3 \pm 1.4$ \\
\hline Medication (yes) & 78 & 438 & \\
\hline Non-opioid & 56 & 314 & $13.0 \pm 37.2$ \\
\hline Weak opioid & 11 & 100 & $27.6 \pm 34.6$ \\
\hline Strong opioid & 2 & 5 & $5.0 \pm 1.4$ \\
\hline Antidepressants & 2 & 15 & $42.0 \pm 28.2$ \\
\hline Other & 9 & 59 & $4.5 \pm 11.5$ \\
\hline Self-treatment (yes) & 131 & 776 & \\
\hline Heat pack & 47 & 346 & $20.0 \pm 42.1$ \\
\hline Bed rest & 24 & 116 & $7.0 \pm 7.5$ \\
\hline Light exercise & 60 & 407 & $26.0 \pm 47.5$ \\
\hline Hot shower & 50 & 290 & $23.9 \pm 55.6$ \\
\hline $\begin{array}{l}\text { Book and reading } \\
\text { information }\end{array}$ & 7 & 16 & $4.0 \pm 2.9$ \\
\hline Other & 25 & 108 & $8.3 \pm 13.6$ \\
\hline
\end{tabular}

*Intensity measured on scale $0-10$.

LBP, low back pain.

participants were asked about their LBP status (yes/no). In case participants reported having LBP during the week, other subsequent questions were asked, such as "could you please recall whether you were doing any of these tasks 2 hours before your LBP started?' (eg, bending, doing moderate physical activity, etc), the number of days suffering with the symptoms, pain intensity using the 0-10 NPRS, and activity limitation due to LBP (yes/or). If a participant's answer was affirmative for activity limitation, then subsequent questions regarding which types of activities (eg, work, socialisation, sports) and the number of days limited were asked. Furthermore, participants reporting LBP were asked whether they had sought treatment during the week (yes/no), which healthcare professional they saw (eg, General practitioner, physiotherapist) and the frequency of treatment during the week. Lastly, participants were asked regarding any self-treatment or medication (including types of medication) used due to LBP and the frequency.

Monthly data on physical activity was collected with the electronic version (through an email link) of the IPAQ questionnaire, asking about the frequency (days) and duration of engagement in physical activity of various intensities (low, light, moderate and vigorous) in the last 7 days. Participants also received a midterm questionnaire (6 months follow-up) that collected the same data as the baseline questionnaire, except for the ActiGraph data. Table 1 presents the timeline for data collection at the baseline, weekly, monthly and midterm follow-ups.

\section{FINDINGS TO DATE}

\section{Sample characteristics}

A total of 401 participants have consented to participate in the study and completed the baseline questionnaire to date. From those, $157(\mathrm{n}=314)$ are complete twin pairs (both twins in the pair were included and provided data) and 87 individual twins (only one twin in the pair was included). A total of 262 monozygotic twins (MZ) and 139 dizygotic twins (DZ) were included. The majority of the sample was female $(73 \%)$ and non-smoker $(82 \%)$. The mean age was $53(\mathrm{SD}=13)$ years old, with a mean $\mathrm{BMI}$ of $25 \mathrm{~kg} / \mathrm{m}^{2}(\mathrm{SD}=4)$ (table 1). Overall, participants reported a normal mean score on DASS in all three DASS components: depression: $3.8 \quad(\mathrm{SD}=6.7)$, anxiety: $3.2 \quad(\mathrm{SD}=5.4)$ and stress: $7.3 \quad(\mathrm{SD}=7.6)$. Overall participants reported poor sleep quality with a mean PSQI score of $6.4(\mathrm{SD}=3.1)$ (table 2).

\section{Baseline data \\ LBP outcomes}

Table 3 presents the data on LBP status at baseline for all participants stratified by complete pairs (data available from both twins in a pair) and individual twins (data available from only one twin in a pair). The inclusion of single twin pairs (individual twins) increases the study sample size and statistical power. For instance, twins can also be analysed as individuals using statistical techniques that account for the paired structure of the data, which can be an important as a first step in estimating the strength of an association before controlling for familial confounding. This association is further compared with subsequent analyses which only complete pairs are included and 
therefore adjusted for early shared environmental and genetic factors $\left(50 \%\right.$ for $\mathrm{DZ}$ and $100 \%$ for MZ ${ }^{43}$

The majority of the cohort $(85 \%(n=342))$, reported having at least one episode of LBP during their lifetime, of which $186(55 \%)$ participants had usual activities limited because of LBP, and $162(48 \%)$ reported having had a recent LBP episode (within the last 4 weeks). From those 162 participants, 43 (27\%) individuals reported being currently receiving some form of treatment, and $95(62 \%)$ reported suffering from pain for at least 3 months. The average pain score on an 11-point scale was $3.0(\mathrm{SD}=1.8)$ for those who reported having LBP in the last 4 weeks. Considering all 401 participants included in the study, a total of 174 twin individuals (52\%; $106 \mathrm{MZ}$; 68 DZ) reported a history of LBP (lifetime prevalence) but were pain-free in the last 4 weeks.

The cohort comprises 157 complete twin pairs (314 twins), of which 120 pairs (240 twins) are concordant for lifetime prevalence of LBP (ie, both twins in the pair reported having or not LBP); while 27 pairs (54 twins) were discordant (ie, one twin in the pair reported no previous episode of LBP during his/her life, whereas the other twin did). Considering those who answer the question of having LBP in the past 4 weeks (262 twins), 52 pairs $(\mathrm{n}=104)$ were discordant, while $24(\mathrm{n}=48)$ and $31(\mathrm{n}=62)$ twin pairs were concordant for having had and not having had LBP, respectively. In general, among participants who reported LBP in the last 4 weeks, $59 \%$ reported suffering from pain that lasted for at least 3 months. From those who reported pain in the last 4 weeks, $33 \%$ were receiving some form of treatment for their LBP. In addition, considering all 157 complete pairs, a total of 31 twin pairs $(n=62$; $44 \mathrm{MZ}$ and $18 \mathrm{DZ}$ ) reported a history of LBP but were pain-free in the last 4 weeks (table 3 ).

\section{Physical activity}

Objective and self-reported data on physical activity are reported in table 4 . Overall, $369(92 \%)$ from the total cohort of 401 participants provided valid accelerometer data. In general, participants spent $61 \%, 35 \%$ and $4 \%$ of their time awake time in sedentary, light, and moderate/ vigorous intensity, respectively. The average number of steps per day was $7779(\mathrm{SD}=3278)$. Based on the WHO recommendations of $10000 /$ day $^{44}$ for individuals to be classified as physically active, only $23 \%(n=85)$ of the sample met the recommendations. The IPAQ long-form showed that participants on average spent more time in sedentary activities (sitting=2516 $(\mathrm{SD}=1353) \mathrm{min} /$ week) than in a combination of walking, moderate, and vigorous activities (total=1465 ( $\mathrm{SD}=1489 \mathrm{~min}$ / week)). When considering different types of physical activity domains (work, transportation, domestic and leisure time), participants were more active during work (1939 (SD=4972 MET-min/week)) and domestic (2006 $(\mathrm{SD}=2784 \mathrm{MET}-\mathrm{min} /$ week $)$ ) related activities than in transportation $((698 \mathrm{SD}=1101))$ or leisure time (1421 $\mathrm{SD}=2005)$ ) activities. The mean score for the Physical Workload Index was $11.4 \pm 9.1$ (range of 0 to 56 ), with higher scores representing greater mechanical loads on the spine associated with body posture and weight lifting during work (table 4).

\section{Response rate and weekly data on LBP}

Although study recruitment is completed, the weekly and monthly data collection are currently underway (as of 30 October 2019). To date, 168 (41\%) participants have completed the 12-month follow-up. Overall, these 168 participants received a total of 7150 text messages, with 6945 being responded, resulting in a completion rate of $97 \%$. Table 5 shows the LBP weekly status for participants who completed the 12-month follow-up. A total of 131 participants $(78 \%)$ reported pain in at least 1 week from those who completed a 12-month follow-up. The yearly average of days reporting pain (considering only those who reported LBP during at least 1 week) was 35.1 $(\mathrm{SD}=56.0)$ days per participant, with an average intensity of $3.2(\mathrm{SD}=1.8)$ on the $0-10$ NPRS. Seventy participants (54\% of those reporting LBP during at least 1 week) reported activity limitation due to LBP. A total of 55 participants sought care for their LBP, representing $42 \%$ of those who reported suffering from LBP during at least 1 week. Physiotherapists were the most commonly seen healthcare professionals (total of 97 consultations) with a yearly average of $4.4(\mathrm{SD}=6.2)$ days of physiotherapy. Seventy-eight participants $(60 \%$ of those reporting LBP during at least 1 week) reported having used some form of pain medication, with non-opioids being the most frequently used, with an average per year of 13.0 \pm 37.2 days for those participants who reported LBP and used non-opioids for at least 1 week. Moreover, 131 participants reported practising some form of self-treatment (eg, using a hot package) during at least 1 week.

\section{Response rate and monthly data}

Considering participants $(\mathrm{n}=168)$ who have completed the 12-month follow-up, 1905 monthly online IPAQ physical activity questionnaires were sent, of which 1763 were answered, resulting in a completion rate of $92 \%$. The monthly average physical activity engagement was categorised into low, moderate, and high intensity per each completed monthly questionnaire.

The average time (minutes per week) of physical activity participation was: low intensity activity $=206 \pm 216$, moderate intensity $=109 \pm 176$ and vigorous intensity $=80$ \pm 143 .

\section{STRENGTHS AND LIMITATIONS}

A key strength of the AUTBACK study is the feature of a cohort of twins with frequent data on LBP and physical activity, with participants representing a variety of LBP phenotypes, including those with a history of activitylimiting LBP, current LBP, no previous history or current LBP and a previous history of LBP but fully recovered. Another novelty of the study is the assessment of different physical activity domains and the frequent assessments 
Table 6 Possible futures studies using the AUTBACK data

\begin{tabular}{|c|c|c|c|}
\hline Research question & Description & Design & Features \\
\hline Risk of LBP & $\begin{array}{l}\text { What type and dosages of physical } \\
\text { activity is a risk or protective for } \\
\text { LBP? }\end{array}$ & Longitudinal & $\begin{array}{l}\text { Participants reporting being free of LBP at } \\
\text { baseline. Outcome: incidence of LBP during } \\
\text { follow-up }\end{array}$ \\
\hline $\begin{array}{l}\text { Prognosis of LBP and } \\
\text { physical activity }\end{array}$ & $\begin{array}{l}\text { Effect of physical activity on LBP } \\
\text { prognosis }\end{array}$ & Longitudinal & $\begin{array}{l}\text { Participants reporting LBP in the past } 4 \\
\text { weeks at baseline. Outcome: recovery of } \\
\text { LBP at follow-up }\end{array}$ \\
\hline $\begin{array}{l}\text { Medication intake and } \\
\text { physical activity }\end{array}$ & $\begin{array}{l}\text { Does physical activity reduce } \\
\text { medication intake in people with } \\
\text { LBP? }\end{array}$ & Longitudinal & $\begin{array}{l}\text { Participants with LBP at baseline. } \\
\text { Outcomes medication intake during follow- } \\
\text { up }\end{array}$ \\
\hline Trajectory of LBP & Trajectories of LBP & Longitudinal & Participants with LBP at baseline \\
\hline $\begin{array}{l}\text { Recurrence of LBP } \\
\text { and physical activity: } \\
\text { controlling for familial } \\
\text { factors }\end{array}$ & $\begin{array}{l}\text { Types and dosages of physical } \\
\text { activity and recurrence of LBP: twin- } \\
\text { case control }\end{array}$ & $\begin{array}{l}\text { Longitudinal } \\
\text { Case-control }\end{array}$ & $\begin{array}{l}\text { Twin pairs with a history of LBP, concordant } \\
\text { for LBP free status at baseline and } \\
\text { discordant for recurrent LBP }\end{array}$ \\
\hline $\begin{array}{l}\text { Low back pain and } \\
\text { care-seeking behaviour: } \\
\text { controlling for familial } \\
\text { factors }\end{array}$ & $\begin{array}{l}\text { Types and dosages of physical } \\
\text { activity and care-seeking for LBP: } \\
\text { twin case-control }\end{array}$ & $\begin{array}{l}\text { Longitudinal } \\
\text { Case-control }\end{array}$ & $\begin{array}{l}\text { Twin pairs with a history of LBP, concordant } \\
\text { for LBP free status at baseline but } \\
\text { discordant for care-seeking }\end{array}$ \\
\hline
\end{tabular}

AUTBACK, AUstralian Twin BACK; LBP, low back pain.

of physical activity and LBP status, with the additional possibility of controlling for the influences of genetic and familial factors in analytical models. The cohort presents a variety of opportunities for study designs and data analyses. For instance, twin pairs concordant for a history of LBP but free of LBP at baseline (both twins in the pair recovered from an episode of LBP) provide the opportunity to investigate if the amount of time spent in different forms of physical activity (eg, vigorous, light, moderate) at baseline (objectively measured) predicts the intensity of pain measured repeatedly over 12 months when controlling for familial factors. Conversely, due to the large number of frequent assessments of LBP and selfreported physical activity, it is also possible to investigate the trajectory of pain in relation to the pattern of physical activity engagement over time and the contribution of genetics and the early familial environment on participants' trajectory of symptoms. More examples of study designs that can be implemented with AUTBACK data are provided in table 6 .

The study employs objective and self-reported measures comprising different physical activity domains (work related, home, transportation and leisure), which will provide data for the investigation of the types and dosages that may prevent, cause or worsen LBP. In additional, there is an opportunity to obtain participants' occupation data from TRA to investigate the effect of different types of physical activity on different working groups, given that different occupations are likely to benefit from, or to be harmed by, different types and amounts of physical activity. ${ }^{45}$ AUTBACK data will also be important to frame physical activity (eg, leisure/work-related physical activity), as well as physical behaviour (physical activity and sedentary time) as compositional analysis, which can be considered for the implementation of future studies. The study also collects data on comorbidities and lifestyle factors such as stress and depression, sleep quality and smoking, which can allow for the effective control these confounders in future analyses. Moreover, the use of an online data collection system yielded a high response rate and made it possible to include participants across Australia, regardless of their location (rural or urban) or age-making this a representative and comprehensive cohort.

A potential limitation of the AUTBACK study is that ActiGraph data were only collected at baseline. We also collected objective data on physical activity from participants at the 6 month follow-up for a subsample of 140 participants. However, we received feedback from participants that wearing the device twice during the study was too burdensome, and therefore, we decided to remove the ActiGraph measurement at the 6-month-follow up to minimise the burden on participants and optimise response rates for the questionnaires. Furthermore, at baseline, not all participants provided valid objective data of physical activity (ActiGraph). The ActiGraph devices 
were mailed to participants, but 12 ActiGraph units were damaged or lost, and not all participants achieved the minimum validation wearing time. However, the total number of participants $(\mathrm{n}=369)$ who worn the device is a representative sample for this study, and completeness rate was higher $(92 \%)$ when compared with other similar studies that employed objective assessment of physical activity reporting response rates of $66 \%-90 \% .{ }^{46-49}$ Another limitation of the study is that we do not have access to the data for those participants that did not express interest in participating in the study due to ethical reasons, and therefore, it is not possible to perform a response analysis on included and non-included participants.

\section{FUTURE DIRECTIONS AND COLLABORATIONS}

We expect to complete the 12-month follow-up for the whole sample by July 2020 . Since this cohort is composed of participants with various LBP status, we will be able to answer various questions regarding the relationship between physical activity and LBP according to the participant's pain status. The AUTBACK working group is designing a series of research projects, with the main one being the investigation of the relationship between different types or dosages of physical activity and recurrence of LBP in people with a history of LBP but symptomfree at study baseline. The advantage of having both twins in a pair enables a higher level of adjustment for genetic and early shared environmental confounders in the analyses. As a result, twin samples commonly enable a more precise estimate of environmental effects (eg, physical activity), with greater statistical power compared with non-twin studies. ${ }^{23}$

We also plan to investigate factors that may influence care-seeking behaviour associated with LBP (eg, healthcare visits and use of pain medication). Data linkage opportunities that are possible through TRA include statelevel patient and hospitalisation data and nationwide data from the Medicare benefits Schedule, the Pharmaceutical Benefits Scheme and data from other studies conducted by TRA. This could allow for new research questions to be explored, bringing additional value to the AUTBACK study and potentially making it a compelling resource from researchers in other disciplines. AUTBACK can also be combined with other international cohorts that have collected similar data, including data on LBP and physical activity. We did not collect biosamples, although this could be undertaken by future researchers who could consider linking biosample data to the current available data collected in AUTBACK. The AUTBACK team welcomes collaboration and research proposals from researchers with expertise in LBP.

AUTBACK is a cohort of participants with objective and self-reported data on different types and domains of physical activity and frequent data on LBP presentation and associated care-seeking behaviour. The study will provide high-quality data for the investigation of the relationship between physical activity and LBP while controlling for important confounders, including genetic and other familial factors.

\section{Author affiliations}

${ }^{1}$ Musculoskeletal Health Research Group, Faculty of Medicine and Health, School of Health Sciences, The University of Sydney, Sydney, New South Wales, Australia ${ }^{2}$ Institute for Musculoskeletal Health, The University of Sydney and Sydney Local Health District, Sydney, New South Wales, Australia

${ }^{3}$ Faculty of Medicine and Health, School of Public Health, The University of Sydney, Sydney, New South Wales, Australia

${ }^{4}$ Institute of Bone and Joint Research, The Kolling Institute, Northern Clinical School, Faculty of Medicine and Health, The University of Sydney, Sydney, New South Wales, Australia

${ }^{5}$ Neuroscience Research Australia, Sydney, New South Wales, Australia

${ }^{6}$ Centre for Epidemiology and Biostatistics, Melbourne School of Population and Global Health, The University of Melbourne, Melbourne, Victoria, Australia ${ }^{7}$ Charles Perkins Centre, The University of Sydney, Sydney, New South Wales, Australia

Acknowledgements The authors thank all participants in this study and Twin Research Australian for all support. APC-e-S holds the Research Training Programme Stipend (International), The University of Sydney. MP is funded by NHMRC Early Career Fellowship. PF is funded by an NHMRC Research Fellowship and University of Sydney SOAR Fellowship. MF holds an MRFF/NHMRC Career Development Fellowship and is a Sydney Medical Foundation Fellow.

Contributors APC-e-S: conducted and supervised the study; analysed the data; drafted, reviewed, and edited the manuscript; MP: designed, implementation of the study, conducted the study; reviewed and edited the manuscript; MF: designed the study, reviewed and edited the manuscript; LC-F: implementation of the study, reviewed and edited the manuscript, MH: designed the study, reviewed and edited the manuscript PF: designed, implementation and supervision of the study; reviewed the manuscript. All authors: read and approved the final manuscript.

Funding This study was funded by a Sydney University National Health and Medical Research Council (NHMRC) bridging grant (APP1086738).

\section{Competing interests None declared.}

Patient and public involvement Patients and/or the public were not involved in the design, or conduct, or reporting, or dissemination plans of this research.

\section{Patient consent for publication Not required.}

Ethics approval The study was approved by TRA and the University of Sydney Human Ethics Committee (Project No: 2015/407). All participants gave consent before data collection began.

Provenance and peer review Not commissioned; externally peer reviewed. Data availability statement № data are available.

Open access This is an open access article distributed in accordance with the Creative Commons Attribution Non Commercial (CC BY-NC 4.0) license, which permits others to distribute, remix, adapt, build upon this work non-commercially, and license their derivative works on different terms, provided the original work is properly cited, appropriate credit is given, any changes made indicated, and the use is non-commercial. See: http://creativecommons.org/licenses/by-nc/4.0/.

\section{ORCID iD}

Ana Paula Carvalho-e-Silva http://orcid.org/0000-0002-0079-4862

\section{REFERENCES}

1 Hoy D, Bain C, Williams G, et al. A systematic review of the global prevalence of low back pain. Arthritis Rheum 2012;64:2028-37.

2 Australian Institute of Health and Welfare (AlHW). Impacts of chronic back problems. Canberra, 2016: 1-15.

3 Hartvigsen J, Hancock MJ, Kongsted A, et al. What low back pain is and why we need to pay attention. Lancet 2018;391:2356-67.

4 Buchbinder R, van Tulder M, Öberg B, et al. Low back pain: a call for action. Lancet 2018;391:2384-8.

5 Taylor JB, Goode AP, George SZ, et al. Incidence and risk factors for first-time incident low back pain: a systematic review and metaanalysis. Spine J 2014;14:2299-319. 
6 Parreira P, Maher CG, Steffens D, et al. Risk factors for low back pain and sciatica: an umbrella review. Spine J 2018;18:1715-21.

7 Becofsky K, Baruth M, Wilcox S. Physical activity mediates the relationship between program participation and improved mental health in older adults. Public Health 2016;132:64-71.

8 Brown DR, Carroll DD, Workman LM, et al. Physical activity and health-related quality of life: US adults with and without limitations. Qual Life Res 2014;23:2673-80.

9 O'Donovan G, Lee I-M, Hamer M, et al. Association of "weekend warrior" and other leisure time physical activity patterns with risks for all-cause, cardiovascular disease, and cancer mortality. JAMA Intern Med 2017; 177:335-42.

10 Hamer M, Ingle L, Carroll S, et al. Physical activity and cardiovascular mortality risk: possible protective mechanisms? Med Sci Sports Exerc 2012;44:84-8.

11 Chudasama YV, Khunti KK, Zaccardi F, et al. Physical activity, multimorbidity, and life expectancy: a UK Biobank longitudinal study. BMC Med 2019;17:108.

12 Chetty L. A critical review of low back pain guidelines. Workplace Health Saf 2017;65:388-94.

13 Pinto RZ, Ferreira PH, Kongsted A, et al. Self-reported moderate-tovigorous leisure time physical activity predicts less pain and disability over 12 months in chronic and persistent low back pain. Eur J Pain 2014;18:1190-8.

14 Shiri R, Falah-Hassani K. Does leisure time physical activity protect against low back pain? systematic review and meta-analysis of 36 prospective cohort studies. Br J Sports Med 2017:51:1410-8.

15 Hübscher M, Ferreira ML, Junqueira DRG, et al. Heavy domestic, but not recreational, physical activity is associated with low back pain: Australian twin low back pain (AUTBACK) study. Eur Spine $J$ 2014;23:2083-9.

16 Zadro JR, Shirley D, Amorim A, et al. Are people with chronic low back pain meeting the physical activity guidelines? A co-twin control study. Spine J 2017;17:845-54.

17 Jacob T, Baras M, Zeev A, et al. Physical activities and low back pain: a community-based study. Med Sci Sports Exerc 2004;36:9-15.

18 Hendrick P, Milosavljevic S, Hale L, et al. The relationship between physical activity and low back pain outcomes: a systematic review of observational studies. Eur Spine J 2011;20:464-74.

19 Lee PH, Macfarlane DJ, Lam TH, et al. Validity of the International physical activity questionnaire short form (IPAQ-SF): a systematic review. Int J Behav Nutr Phys Act 2011;8:115.

20 Celis-Morales CA, Perez-Bravo F, Ibañez L, et al. Objective vs. self-reported physical activity and sedentary time: effects of measurement method on relationships with risk biomarkers. PLoS One 2012; 7:e36345.

21 Liu S-H, Eaton CB, Driban JB, et al. Comparison of self-report and objective measures of physical activity in US adults with osteoarthritis. Rheumatol Int 2016;36:1355-64.

22 Huijnen IPJ, Verbunt JA, Roelofs J, et al. The disabling role of fluctuations in physical activity in patients with chronic low back pain. Eur J Pain 2009;13:1076-9.

23 Ferreira PH, Beckenkamp P, Maher CG, et al. Nature or nurture in low back pain? results of a systematic review of studies based on twin samples. Eur J Pain 2013;17:957-71.

24 Junqueira DRG, Ferreira ML, Refshauge K, et al. Heritability and lifestyle factors in chronic low back pain: results of the Australian twin low back pain study (the AUTBACK study). Eur J Pain 2014:18:1410-8.

25 Plomin RNJ, Knopick VS, DeFries JC. Behavioral genetics. 7 edn. New York, NY: Worth Publishers, 2016.

26 Pinheiro MB, Ferreira ML, Refshauge K, et al. Protective and harmful effects of physical activity for low back pain: a protocol for the Australian twin back pain (AUTBACK) feasibility study. Twin Res Hum Genet 2016;19:502-9.

27 Knaier R, Höchsmann C, Infanger D, et al. Validation of automatic wear-time detection algorithms in a free-living setting of wrist-worn and hip-worn actigraph GT3X. BMC Public Health 2019;19:244.
28 Santos-Lozano A, Santín-Medeiros F, Cardon G, et al. Actigraph GT3X: validation and determination of physical activity intensity cut points. Int J Sports Med 2013;34:975-82.

29 Migueles JH, Cadenas-Sanchez C, Ekelund U, et al. Accelerometer data collection and processing criteria to assess physical activity and other outcomes: a systematic review and practical considerations. Sports Med 2017;47:1821-45.

30 Troiano RP, McClain JJ, Brychta RJ, et al. Evolution of accelerometer methods for physical activity research. Br J Sports Med 2014;48:1019-23.

31 Choi L, Liu Z, Matthews CE, et al. Validation of accelerometer wear and nonwear time classification algorithm. Med Sci Sports Exerc 2011:43:357-64.

32 Childs JD, Piva SR, Fritz JM. Responsiveness of the numeric pain rating scale in patients with low back pain. Spine 2005:30:1331-4.

33 Deyo RA, Battie M, Beurskens AJ, et al. Outcome measures for low back pain research. A proposal for standardized use. Spine 1998;23:2003-13.

34 Roland M, Morris R. A study of the natural history of back pain. part I: development of a reliable and sensitive measure of disability in lowback pain. Spine 1983;8:141-4.

35 Dionne CE, Dunn KM, Croft PR, et al. A consensus approach toward the standardization of back pain definitions for use in prevalence studies. Spine 2008;33:95-103.

36 Hagströmer M, Oja P, Sjöström M. The international physical activity questionnaire (IPAQ): a study of concurrent and construct validity. Public Health Nutr 2006;9:755-62.

37 Hollmann S, Klimmer F, Schmidt KH, et al. Validation of a questionnaire for assessing physical work load. Scand J Work Environ Health 1999;25:105-14.

38 Besson $\mathrm{H}$, Brage S, Jakes RW, et al. Estimating physical activity energy expenditure, sedentary time, and physical activity intensity by self-report in adults. Am J Clin Nutr 2010;91:106-14.

39 The IPAQ Group. Guidelines for data processing and analysis of the international physical activity questionnaire, 2015.

40 Henry JD, Crawford JR. The short-form version of the depression anxiety stress scales (DASS-21): construct validity and normative data in a large non-clinical sample. Br J Clin Psychol 2005:44:227-39.

41 Buysse DJ, Reynolds CF, Monk TH, et al. The Pittsburgh sleep quality index: a new instrument for psychiatric practice and research. Psychiatry Res 1989;28:193-213.

42 Ahmad N, Adam SIM, Nawi AM, et al. Abdominal obesity indicators: waist circumference or waist-to-hip ratio in Malaysian adults population. Int J Prev Med 2016;7:82.

43 Leite HR, Dario AB, Harmer AR, et al. Contributions of birthweight, annualised weight gain and BMI to back pain in adults: a populationbased co-twin control study of 2754 Australian twins. Eur Spine J 2019;28:224-33.

44 Tudor-Locke C, Bassett DR. How many steps/day are enough? preliminary pedometer indices for public health. Sports Med 2004;34:1-8.

45 Overas CK, Villumsen M, Axen I, et al. Association between objectively measured physical behaviour and neck- and/or low back pain: a systematic review. Eur J Pain 2020.

46 Leininger B, Schulz C, Gao Z, et al. Accelerometer-determined physical activity and clinical low back pain measures in adolescents with chronic or subacute recurrent low back pain. J Orthop Sports Phys Ther 2017;47:769-74.

47 Amorim AB, Pappas E, Simic M, et al. Integrating mobile-health, health coaching, and physical activity to reduce the burden of chronic low back pain trial (impact): a pilot randomised controlled trial. BMC Musculoskelet Disord 2019;20:71.

48 Hendrick P, Milosavljevic S, Hale L, et al. Does a patient's physical activity predict recovery from an episode of acute low back pain? A prospective cohort study. BMC Musculoskelet Disord 2013;14:126.

49 Hashimoto Y, Matsudaira K, Sawada SS, et al. Association between objectively measured physical activity and body mass index with low back pain: a large-scale cross-sectional study of Japanese men. BMC Public Health 2018;18:341. 